\title{
Nanoscale Electrodeposition of Copper on an AFM Tip and Its Morphological Investigations
}

\author{
Udit Surya Mohanty, S. Y. Chen and Kwang-Lung Lin \\ Department of Materials Science and Wngineering, \\ National Cheng Kung University \\ Tainan, \\ R.O.C, Taiwan
}

\section{Introduction}

Electrocrystallisation processes occurring at electrochemical solid/liquid interfaces have attracted the interest of many researchers from both fundamental and applied viewpoints. After the pioneering works of Max Volmer at the beginning of the last century (Volmer, 1934a, 1939b), the processes of electrocrystallisation have been the subject of numerous intensive studies, the results of which have been documented in several books (Bockris \& Razumney 1967; Budevski, et al., 1996; Fischer,1954). The electrochemical method offers several advantages over vapour deposition techniques such as molecular beam epitaxy for depositing nanoscale superlattices. Additional technological advantages over the vapour deposition techniques consist in the relatively low processing temperature and the high selectivity. The low processing temperatures minimizes interdiffusion whereas the high selectivity of electrocrystallisation process allows uniform modification of surfaces and structures with complicated profiles. Phase formation and crystal growth phenomena are the most common morphological parameters observed in many technological important cathodic and anodic electrochemical reactions. One of the most frequently studied electrocrystallisation process is the cathodic metal deposition on foreign and native substrates from electrolytes containing complex metal ions (Fleischmann \& Thirsk, 1963; Milchev, 2002; Paunovic \& Schlesinger, 2006). Some of the typical cited examples are electrocrystallisation of $\mathrm{Ag}$ from $\mathrm{Ag}^{+}$containing electrolytes (Budevski et al., 1980; Fischer, 1969) and the electrodeposition of $\mathrm{Cu}$ (Budevski, 1983; Danilov et al., 1994; Hozzle et al., 1995; Michhailova et al. , 1993) which has recently become technologically important for the fabrication of $\mathrm{Cu}$ interconnects on integrated circuit chips (Andricacos et al., 1998; Oskam et al. 1998). Since the electrodeposition of metals is a process of great technological importance, a large number of studies have been carried out to understand the mechanism of electrodeposition of metals on conducting surfaces by employing a variety of electrochemical and spectroscopic techniques (Andricacos, 1999; Markovic \& Ross, 1993). The conventional electrochemical methods such as cyclic voltammetry, impedance spectroscopy have been used to assess the mechanism and kinetics of metal electrocrystallisation. These techniques however provide information on the whole surface. 
To fully understand the process, it is essential to obtain structural information on the substrate and the deposit in pm to the atomic level. Although techniques such as electron microscopy and optical microscopy have been employed to examine the morphology of the substrate and the metal deposit, they can be used only for the ex situ examination. The discovery of scanning tunnelling microscopy and atomic force microscopy (STM and AFM) offered new exciting possibilties for in situ studies of the electrocrystallisation phenomenon down to an atomic level (Binning \& Rohrer, 1982; Lustenberger et al., 1988, Sonnenfeld \& Hannsma, 1986). The application of these techniques in the last two decades has revolutionized the experimental work in this field and led to significant progress in the understanding of the atomistic aspects of the electrocrystallisation process (Gewirth \& Siegenthaler, 1995; Staikov et al., 1994; Stegenthaler, 1992). These processes range from measuring the lateral force using a cantilever tip, measuring magnetic force, electrostatic force, Kelvin potential to the determination of surface conductivity. The invention of scanning probe microscopy (SPM) also provoked a rapid development of the modern nanoscience and nanotechnology dealing with nanoscale structures and objects including single atoms and molecules. Over, the years, many other types of scanning probe microscopic techniques have evolved from the base concept of AFM. Electrochemical fabrication of metal nanostructures has been reported using SPM-based lithography, typically by tip induced electrochemical deposition of metal ions transferred by the STM or AFM tip to the surface. (Allongne, 1995; Benenz et al., 2002). Many studies have been directed towards in situ STM and AFM imaging of metal underdeposition (Hachiya et al.1991; Li et al., 2001) and bulk deposition (Nichols et al., 1992; Yau et al. 1991). Since STM can only be applied to observe conductive surfaces, the existence of anodic oxide films as well as the space charge layer in the depletion condition makes the STM measurements of semiconductor electrodes relatively difficult (Batina \& Nichols, 1992). On the other hand, AFM can image even non-conducting surfaces and electrochemical processes on the tip, which causes serious problems in the STM measurements in electrolyte solutions. AFM is also found to be more useful than STM in studying the electrode surface in situ. AFM works the same way as STM and can transfer materials from tip to substrate at a biased voltage. As AFM tips are normally made of silicon or silicon nitide, metallic materials have to be coated onto the AFM tip in order to make the deposition happen. Once it is coated with metals, it becomes no different from a STM tip, and deposition takes place under high electric field. AS AFM can work in liquid solution, it is possible to initiate electrochemical deposition using an AFM tip. Also the electrochemical reaction rate at the interface can be controlled by application of an external potential to the substrate. In particular, the amount of deposit and the kinetics of the metal deposition onto the surface can be controlled. Its because the electrochemical process is sensitive to the surface properties, in situ local deposition of metal can be made selective by tuning the surface characteristics. Copper has been electrochemically deposited onto GaAs surface by immersing the AFM tip into a mixture of $\mathrm{CuSO}_{4}+\mathrm{H}_{2} \mathrm{SO}_{4}$ solution (Carlsson et al., 1990).

The electrodeposition of $\mathrm{Cu}$ is strongly dependent on the structure of the substrate, applied potential and concentration of $\mathrm{Cu}^{2+}$ ions in the precursor solution. The nanoscale electrodeposition of metal in nanopatterned alkanethiol-modified Au (III) has been reported (Gewirth \& Sigenthaler, 1995). Although the interaction between the tip and the sample enhanced $\mathrm{Cu}$ deposition on the surface, $\mathrm{Cu}$ did not deposit uniformly in the area scanned, but only deposited at the edges of the scanned area as well as in defects in the alkanethiol 
(self assembled monolayer) (SAM). The authors suggested the physical and electrostatic inhibition by the tip, or the diffusion of $\mathrm{Cu}$ ions to the area under the tip, even on a bare $\mathrm{Au}$ (III) surface. In one of the studies (Koinuma \& Uosaki, 1994), AFM and scaling analysis have been employed to investigate the effect of current density, temperature and levelling agent on the morphology of electrolytically produced copper. However, very little information is available on the morphology of the nanostructures formed by the electrodeposition of copper on the AFM tip. In the present chapter an effort has been made to examine various modes of nucleation and growth of copper deposits on an AFM tip of $80 \mathrm{~nm}$. Electron beam lithography techniques have been employed to facilitate selective electrodeposition of copper on the nanosize AFM tip in the presence of photoresist named poly (methyl methacyrlate).

\section{Experimental method}

In the present study an AFM probe NSC/18 / Ti-Pt was used which consisted of a Si base coated by films of Ti (1st layer, $15 \mathrm{~nm}$ ) and Pt (2ndlayer) $10 \mathrm{~nm}$. The Cantilevers employed were $230 \mu \mathrm{m}$ in length and $40 \mu \mathrm{m}$ in diameter with pyramidal tips of diameter $80 \mathrm{~nm}$. The tip height ranged from 20 to $25 \mu \mathrm{m}$. The schematic diagram of the uncoated AFM probe containing the tip is shown in Fig. 1a. The magnified image is demonstrated in Fig. 1b. One of the AFM probes acted as a anode and the other as a cathode. Two connectors were placed on the AFM probes to facilitate the current flow between the power supplier and the probes, as illustrated in Fig. 2. For the preparation of a connector, a Cu plate of diameter $3.4 \mathrm{~mm}$ and length $12 \mathrm{~mm}$ was first plated with electroless $\mathrm{Au}$ (Fig. 3). The following electrolytic composition was used in the study: $2 \mathrm{~g} / \mathrm{L} \mathrm{KAu}(\mathrm{CN})_{2} ; 75 \mathrm{~g} / \mathrm{L} \mathrm{NH} 4 \mathrm{Cl} ; 50 \mathrm{~g} / \mathrm{L}$ $6 \mathrm{H}_{5} \mathrm{Na}_{3} \mathrm{O}_{7} \cdot 2 \mathrm{H} 2 \mathrm{O}$; and $10 \mathrm{~g} / \mathrm{L} \mathrm{NaH} \mathrm{PO}_{2} \cdot \mathrm{H} 2 \mathrm{O}$. The $\mathrm{pH}$ of the electrolytic solution was maintained at 7 and the solution temperature was kept at $92^{\circ} \mathrm{C}$.

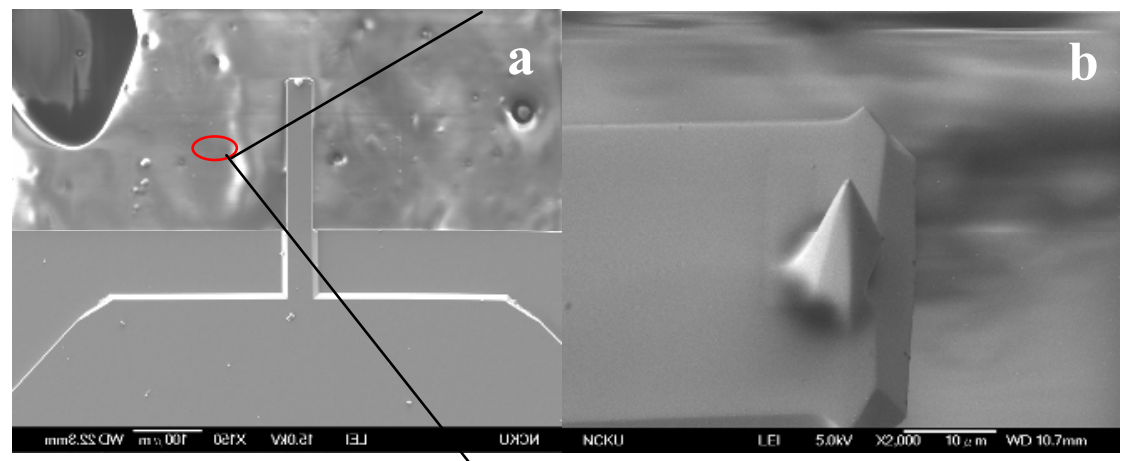

Fig. 1. SEM micrograph illustrating the schematic representation of an uncoated AFM probe

The layer of electroless gold on the copper plate provided good adhesion. The $\mathrm{Cu}$ plate coated with electroless $\mathrm{Au}$ was connected to a $\mathrm{Cu}$ wire as shown in Fig 3 by means of mechanical force. Finally, the connector was electroplated with a hard layer of Au to provide good abrasion ability and a thicker Au layer. The Si holders and the connectors were fixed together and were placed in a rectangular cell containing the electrolyte of composition $80 \mathrm{~g} / \mathrm{L} \mathrm{CuSO}_{4}$ and $200 \mathrm{~mL} / \mathrm{L} \mathrm{H}_{2} \mathrm{SO}_{4}$. The power supply was fixed in the range 
of $10 \mu \mathrm{A}$ to $100 \mathrm{~A}$. Because the AFM probes cannot bear large amounts of current, a large electrode system consisting of $\mathrm{Pt}$ anode and $\mathrm{Cu}$ cathode was used as shown in Fig. 4.

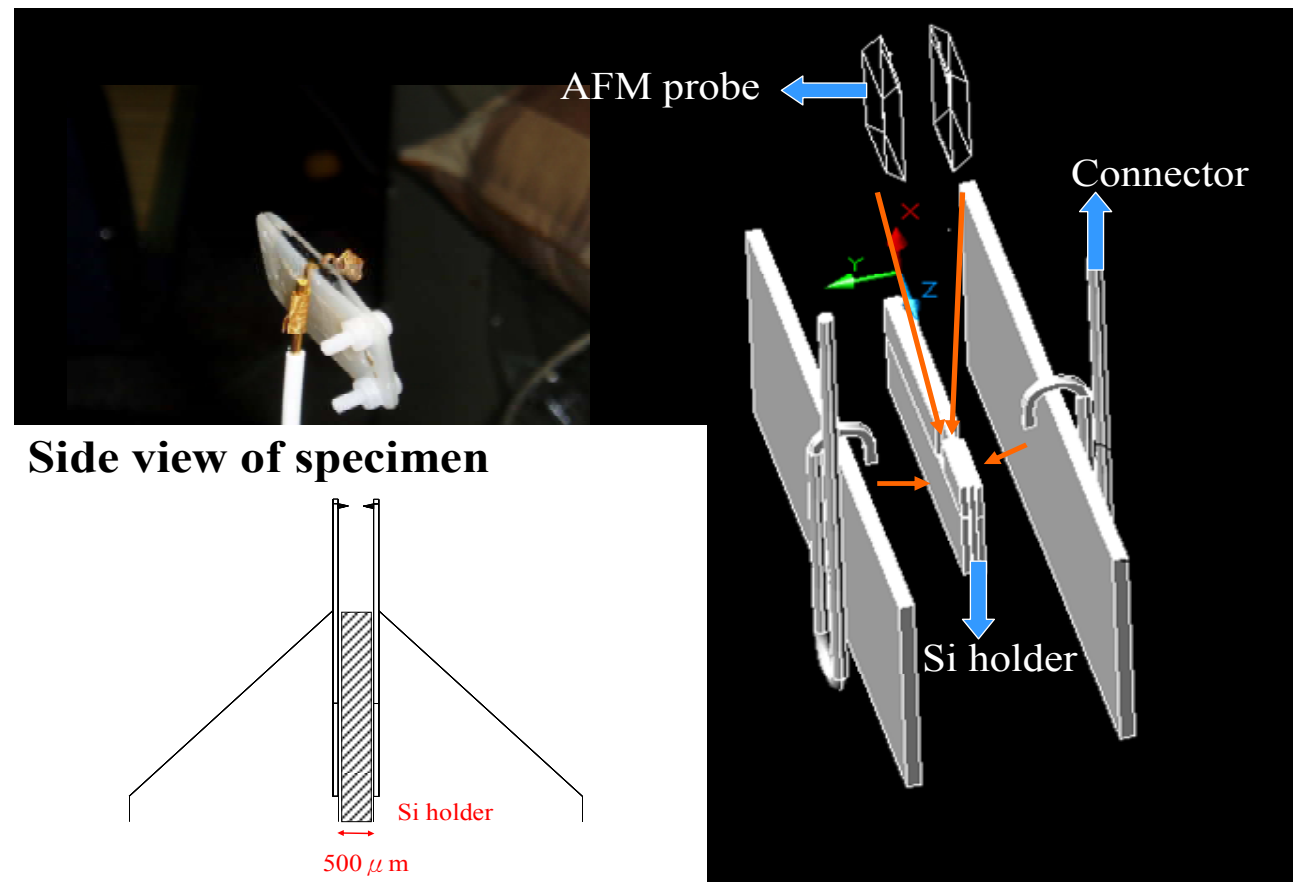

Fig. 2. Schematic diagram of the AFM probe placed on the Si holder

The cathode and anode were placed in parallel connection with the AFM probes.The current from the power supply was controlled between 10 and $0.1 \mathrm{~A}$ to provide a stable current between the AFM probes. Electron-beam lithography (EBL) techniques were used in our present work.

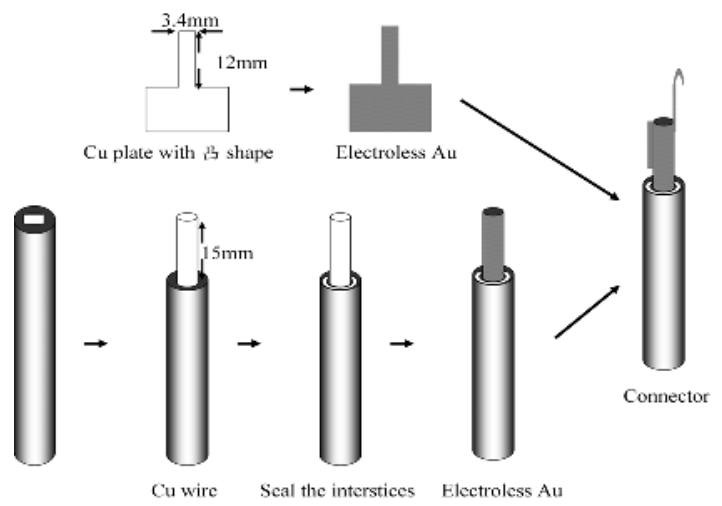

Fig. 3. Schematic diagram of the connector used in the electrodeposition process 


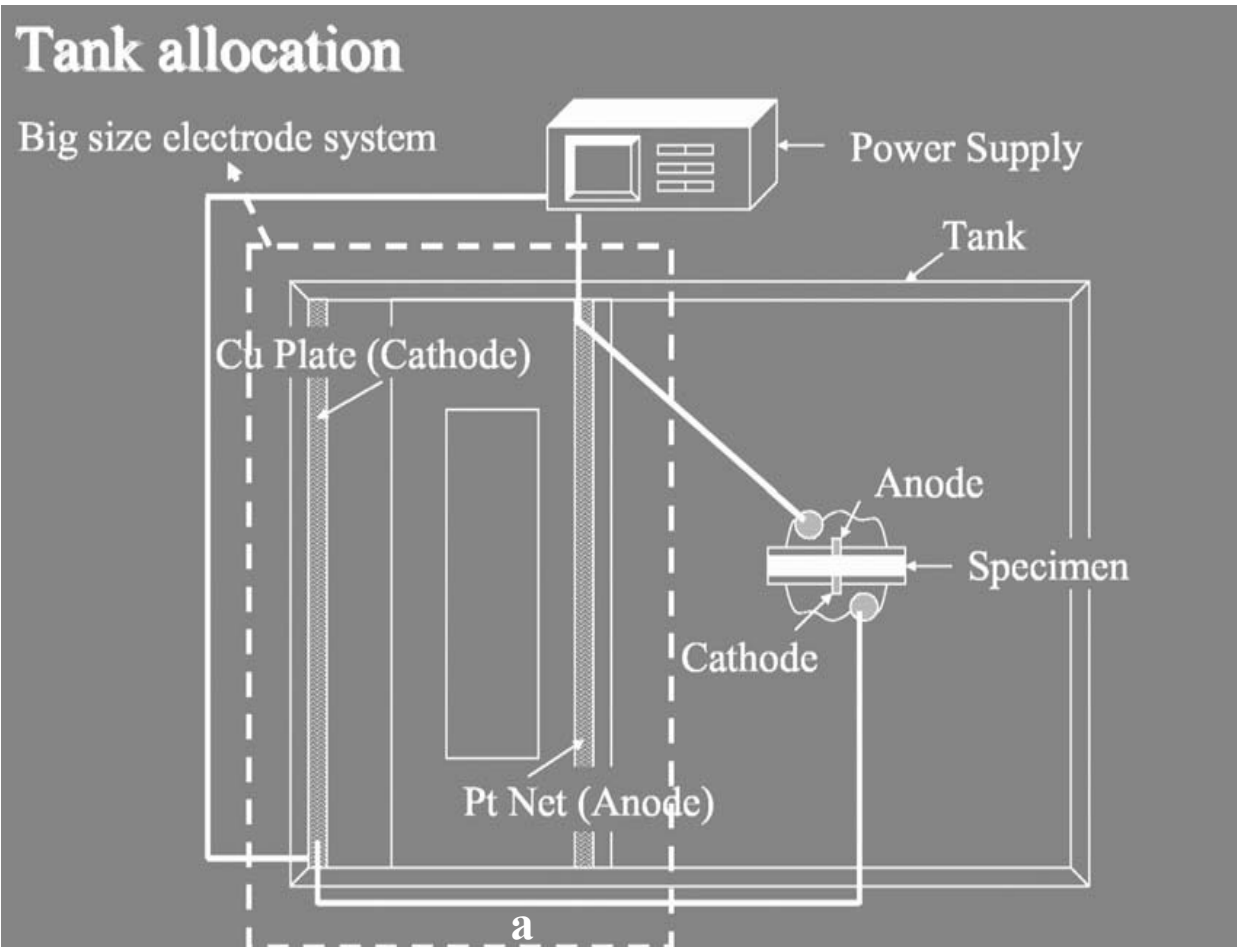

Fig. 4. Schematic diagram demonstrating the electrodeposition of copper on the AFM probe.

The samples were patterned using a JEOL 6400 thermionic emission scanning electron microscope equipped with the lithography software Elphy Quantum. The polymer used for EBL studies was poly_methyl methacrylate (PMMA). PMMA was the standard positive ebeam resist dissolved in a casting solvent anisole. The PMMA solution was spin-coated onto the AFM probe at a rotating speed of $1000 \mathrm{rpm}$ for $60 \mathrm{~s}$. Then baking was performed at $220^{\circ} \mathrm{C}$ to harden the film and to remove the remaining solvent. The EBL system employed a focused electron beam which moved across the sample to selectively expose a pattern in the resist previously designed with the system's built-in computer-assisted design tools. The open area of the AFM tip was selectively exposed to the high energy- beam electrons. The sample was then immersed in the developer solution (3:1 methyl isobutyl ketone: isopropyl alcohol developer) for $30 \mathrm{sec}$ to selectively remove the resist from the exposed areas, whereas the unexposed resist remained insoluble in the developer. The process thus left a patterned resist mask on the sample that could be used for further processing. Finally, $\mathrm{Cu}$ was electrochemically deposited on the AFM tip.

\subsection{Effect of various electrodeposition parameters}

\subsubsection{Effect of current density on copper electrodeposition}

Scanning Electron Microscopy (SEM) was used to investigate the morphologies of the copper deposits nucleated on the AFM probe. SEM micrograph for $\mathrm{Cu}$ deposition on the 
investigated AFM probe for a plating time of $300 \mathrm{~s}$ and a current density of $0.03 \mathrm{~A} / \mathrm{dm}^{2}$ is shown in Fig. 5a. The secondary electron image (SEI) and back scattered electron image (BEI) are displayed in Figs. 5a and 5b. The figure reveals that only a slight amount of copper is electrodeposited on the AFM probe. Further increase in current density to $0.3 \mathrm{~A} / \mathrm{dm}^{2}$ enhanced the copper deposition on the AFM probe however the deposits observed are nonuniform and discontinuous (Fig.6a). The magnified image is seen in Fig. 6b. Furthermore, a gradual increase in the current density to $0.6 \mathrm{~A} / \mathrm{dm}^{2}$ results in uniform deposition of copper on the probe (Fig.7), nevertheless, no copper deposition is noticed on the AFM tip. Similar observations have been reported (Seah et al., 1998). They visualised this morphology on the basis of the fact that formation of more nucleation sites promoted uniform grain growth. In the present study, the formation of uniform copper deposits on the AFM probe could be attributed to the enhanced mass transfer of copper ions with the increase in current density. Litearture reports (Chang, 2001) describe that increase in plating current density increased the surface roughness and reduced the grain size of copper films due to an increase of plating overpotential. Several other researchers have demonstrated that the polarization overpotential increased with increasing the plating current density leading to high copper nucleation rate (Takahashi \& Gross, 1999a, 2000 b; Tean et al., 2003; Teh et al., 2001).

The difficulty in depositing $\mathrm{Cu}$ ions on the AFM tip arises due to the local increase of the ion concentration in the electrolyte around the tip, which makes the effective local Nernst potential for deposition at the surface underneath the AFM tip more positive.

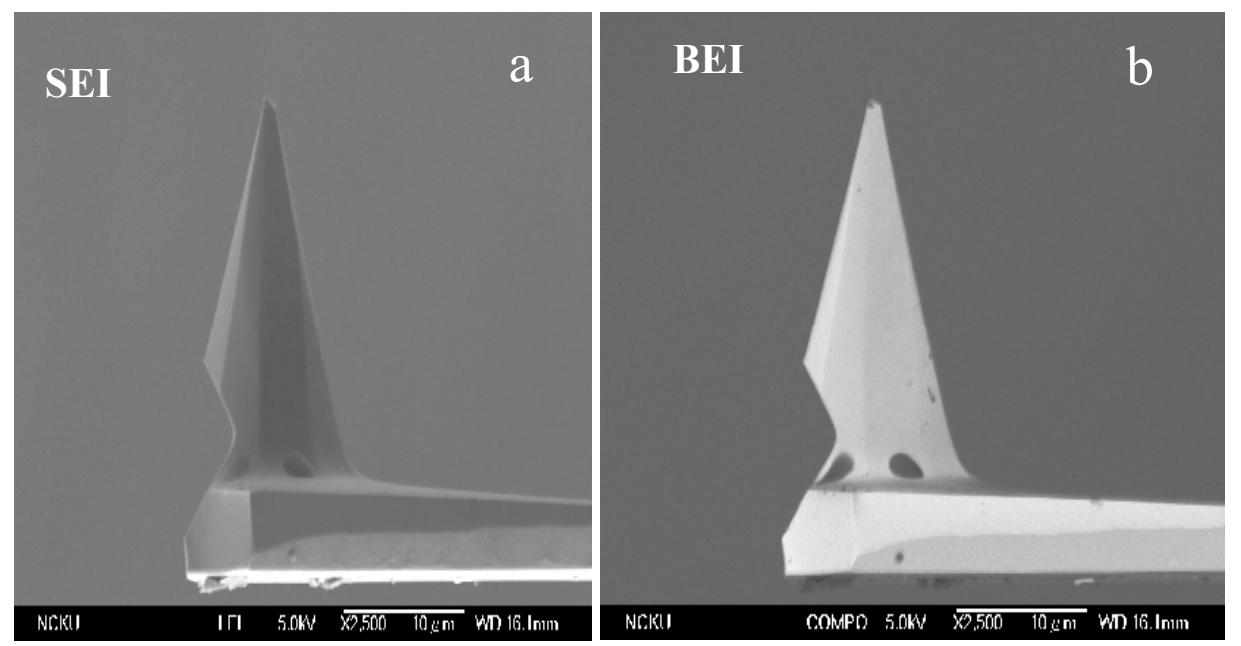

Fig. 5. SEM image obtained after copper deposition on the AFM tip for plating time of $300 \mathrm{~s}$ and current density of $0.03 \mathrm{~A} / \mathrm{dm}^{2}$ (a) SEI image (b) BEI image

Since, the standard electrode potential $\left(\psi^{\mathrm{e}}\right)$ of $\mathrm{Cu}^{2+}\left[\Psi^{\mathrm{e}}\left(\mathrm{Cu}^{2+}+/ \mathrm{Cu}=+0.337 \mathrm{~V}\right)\right.$ is larger than zero (Fu et al., 1990), from the theoretical point of view, the more positive the $\Psi^{\mathrm{e}}$ value, the more easier it is for the reduction of metal ions, and the more negative the $\Psi^{\mathrm{e}}$ value, the more difficult it is to reduce the metal ions. Our results suggest that the copper ions can be reduced to copper atoms more easily on the surface underneath the AFM tip. It might be possible that the effective Nernst potential which is required to initiate nucleation on the 
AFM tip might be larger due to the deposition overvoltages. Also, the diameter of the AFM tip, which is around $80 \mathrm{~nm}$, might induce high overpotential for deposition of copper on the tip.
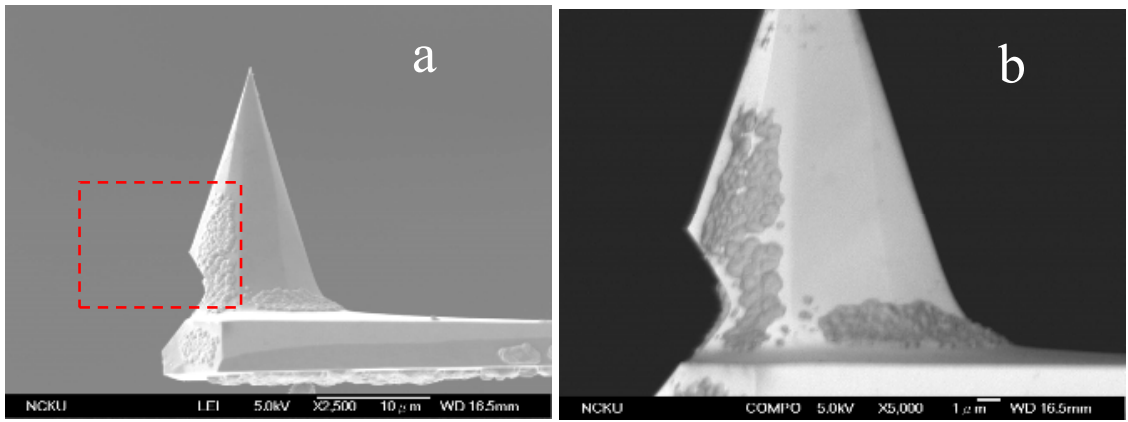

Fig. 6. SEM image obtained after copper deposition on the AFM tip for plating time of $300 \mathrm{~s}$ and current density of $0.3 \mathrm{~A} / \mathrm{dm}^{2}$ (a) SEI image (b) Magnified image (Lin, 2008)

The above results can also be explained on the basis of two reaction schemes which govern the $\mathrm{Cu}$ electrodeposition process on the AFM probe: one is the electrode surface reaction and the other one is the $\mathrm{Cu}^{2+}$ diffusion from the electrolyte solution to the electrode surface.

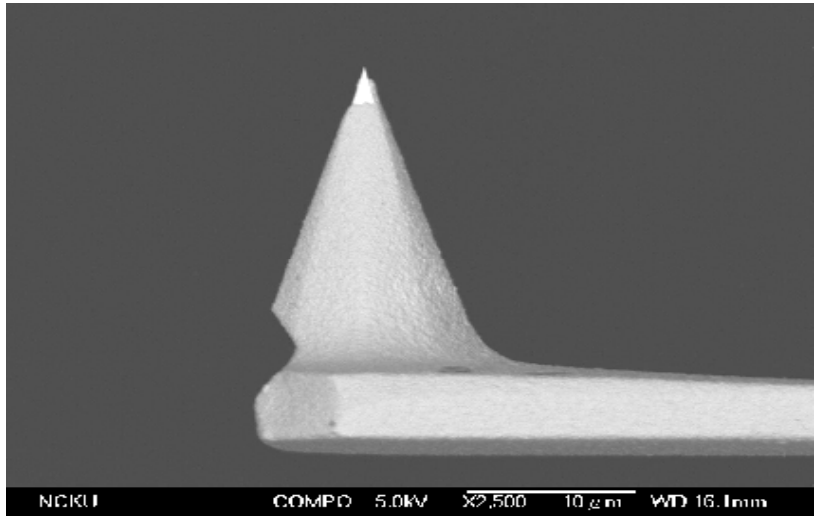

Fig. 7. SEM image obtained after copper deposition on the AFM tip for plating time of $300 \mathrm{~s}$ and current density of $0.6 \mathrm{~A} / \mathrm{dm}^{2}$ (Lin, 2008)

Polarization occurs when the rate of $\mathrm{Cu}^{2+}$ supply from the electrolyte solution is not faster than the rate of reaction at the electrode surface. The film morphology is primarily dependent on the degree of polarization (Seah et al., 1999).Thus higher polarization would make electrodeposition slower resulting in a smoother film. Since the effect of increasing current density is to increase the electrode surface reaction, a faster surface reaction makes $\mathrm{Cu}^{2+}$ undersupplied from the electrolyte solution. Hence, the polarization is higher and smoother film morphology is observed. Nevertheless, when the applied current density is greater than the limiting current density, it is impossible for the electrode to gain any $\mathrm{Cu}$ ions from the electrolyte solution; thereby leading to an increase in the $\mathrm{Cu}$ film surface roughness. 


\subsubsection{Effect of plating time on copper electrodeposition}

The effect of different plating times during copper electrodeposition on the AFM probe is investigated. The plating time was varied from 5 to $900 \mathrm{~s}$ for different current densities. The SEM micrograph in Figs. 8-11 illustrates the morphology of copper deposit formed under current density of $0.3 \mathrm{~A} / \mathrm{dm}^{2}$ and various plating times namely 5, 60, 300, 540 s respectively. The results reveal a random distribution of copper crystals on the cantilever with no trace of copper deposits on the AFM tip. This morphology clearly suggests the case of instantaneous nucleation.

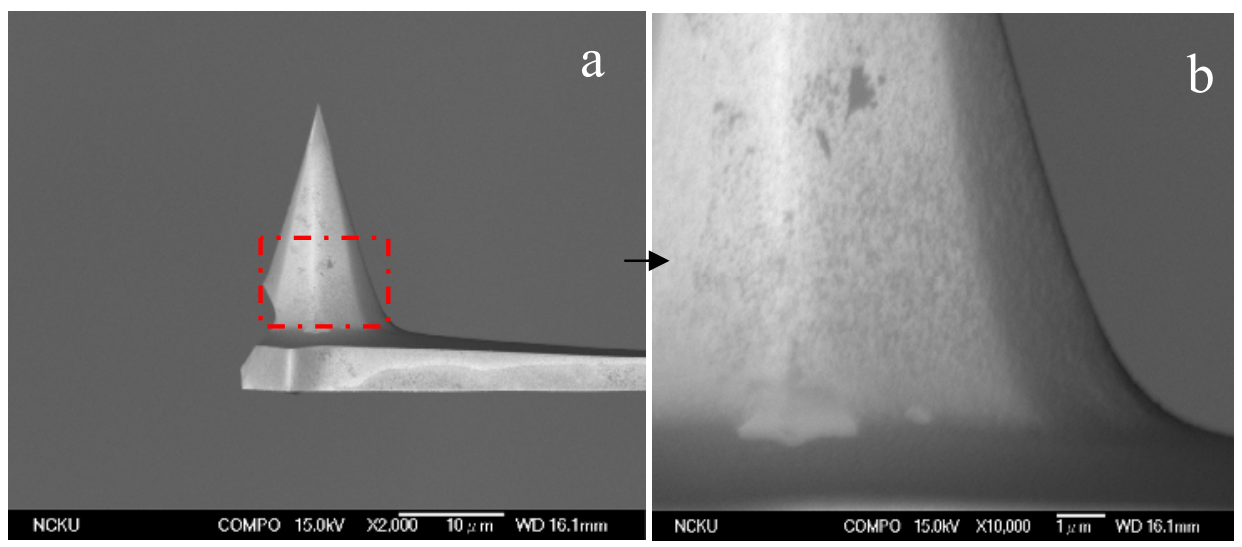

Fig. 8. SEM micrographs illustrating $\mathrm{Cu}$ deposition on the AFM tip at a current density of 0.3 $\mathrm{A} / \mathrm{dm}^{2}$ and plating time of $5 \mathrm{~s} \mathrm{(a)} 2000 \mathrm{~T}$ (b) $10000 \mathrm{~T}$ magnification of the marked area in red

As instantaneous nucleation corresponds to a slow growth of nuclei on a small number of active sites, all activated at the same time. It can be noted from the SEM images displayed in Fig. 8-11, that in most of the samples the nuclei may be nucleated almost simultaneously, as confirmed by their similar size. In other words i.e at high nucleation rates (instantaneous nucleation), all nuclei are formed immediately after imposition of the potential and grow at the same rate. As a result, they are all of the same age and their number remains constant.

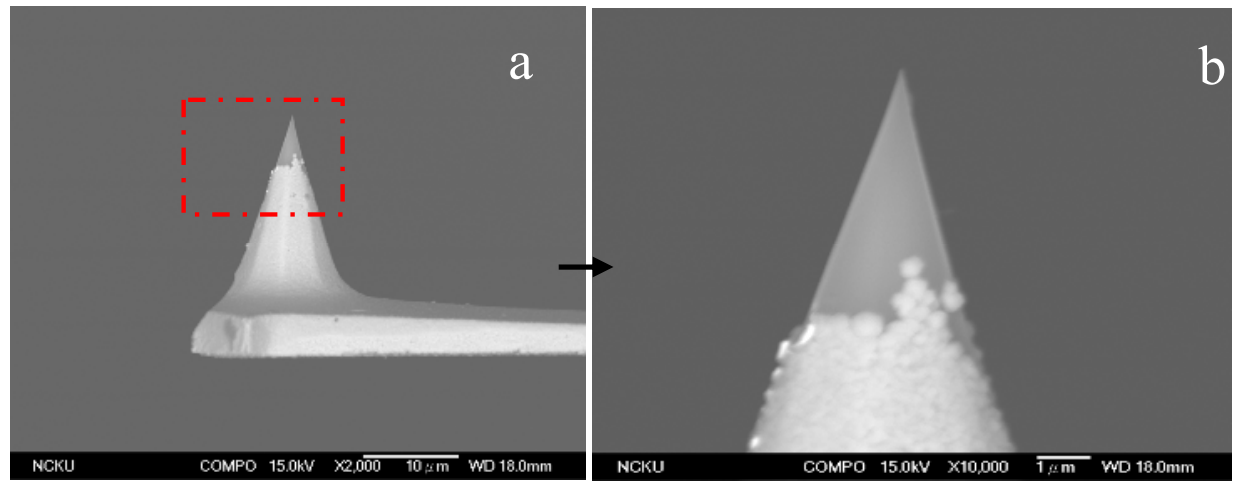

Fig. 9. SEM micrographs illustrating $\mathrm{Cu}$ deposition on the AFM tip at a current density of 0.3 A/ dm² and plating time of $60 \mathrm{~s}$ (a) $2000 \mathrm{~T}$ (b) $10000 \mathrm{~T}$ magnification of the marked area in red 
The mode of instantaneous nucleation is described by the following equation involving the first-order kinetics law (Budevski et al., 1996; Milchev, 1997)

$$
\mathrm{N}=\mathrm{N}_{0}[1-\exp (-\mathrm{At})]
$$

where $\mathrm{N}$ is the number of sites converted into nuclei at time $\mathrm{t}$ and $\mathrm{A}$ is the nucleation rate constant, $\mathrm{N}_{0}$ is the respective saturation value. Nucleation does not occur simultaneously over the entire cathode surface and a diameter distribution for the crystallites ensues. When A is very high, $\mathrm{N} \equiv \mathrm{N}_{0}$, all surface sites are converted immediately into nuclei and the nucleation is said to be instantaneous. The nonhomogeneity and overgrowth of the $\mathrm{Cu}$ deposits may be due to the existence of low nucleation overpotential in the area beneath the tip. At low overpotentials, the nucleation is described well by the model of instantaneous nucleation for reasonably long time scales (Kelber et al., 2006)
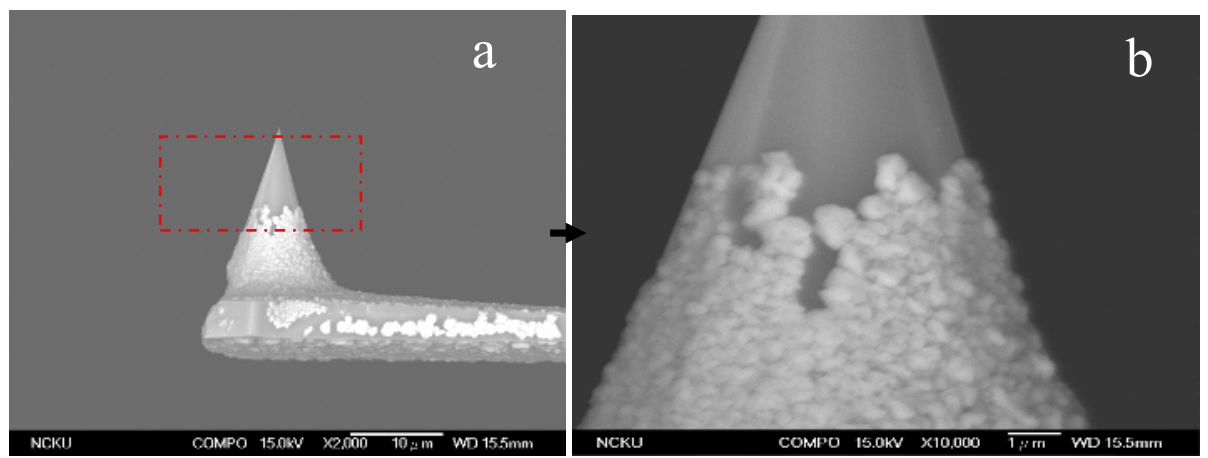

Fig. 10. SEM micrographs illustrating $\mathrm{Cu}$ deposition on the AFM tip at a current density of $0.3 \mathrm{~A} / \mathrm{dm}^{2}$ and plating time of $300 \mathrm{~s}$ (a) $2000 \mathrm{~T}$ (b) $10000 \mathrm{~T}$ magnification of the marked area in red

However, the morphology of copper deposits formed under current density of $0.6 \mathrm{~A} / \mathrm{dm}^{2}$ and plating time of $900 \mathrm{~s}$ were found to be totally different. The copper layer on the AFM probe also shows resemblance to a candle base (Fig. 12), and a thicker layer of copper deposits are grown on the whole of the AFM probe containing the tip. Also, on the basis of instantaneous nucleation model, It has been reported (Thirsk \& Harrison, 1972) that under the diffusion controlled three-dimensional growth, the cathodic current density is proportional to $\mathrm{t}^{1 / 2}$.

The growth of copper layer also takes place slowly and farther away from the tip. Also it can be noticed that the growth rate on the side of tip is faster than on the tip (Fig. 12). From the results it could be established that higher current density and higher plating time increases the mass transfer of $\mathrm{Cu}^{2+}$ ions in the open area beneath the tip, thereby enhancing the rate of $\mathrm{Cu}$ deposition between the open area and the tip. The variance of the thickness of copper deposits on the tip and its surrounding area might be attributed to the nanoscale dimension of the AFM tip as compared to the whole of the AFM probe. Literature reports reveal (Seah et al., 1999) that in case of nanocrystalline electrodeposited $\mathrm{Cu}$ the pinhole number-density necessary for full coverage on the substrate can be reduced by increasing the current density. However, abnormal crystallite growth-leading to the formation of bimodal grain 


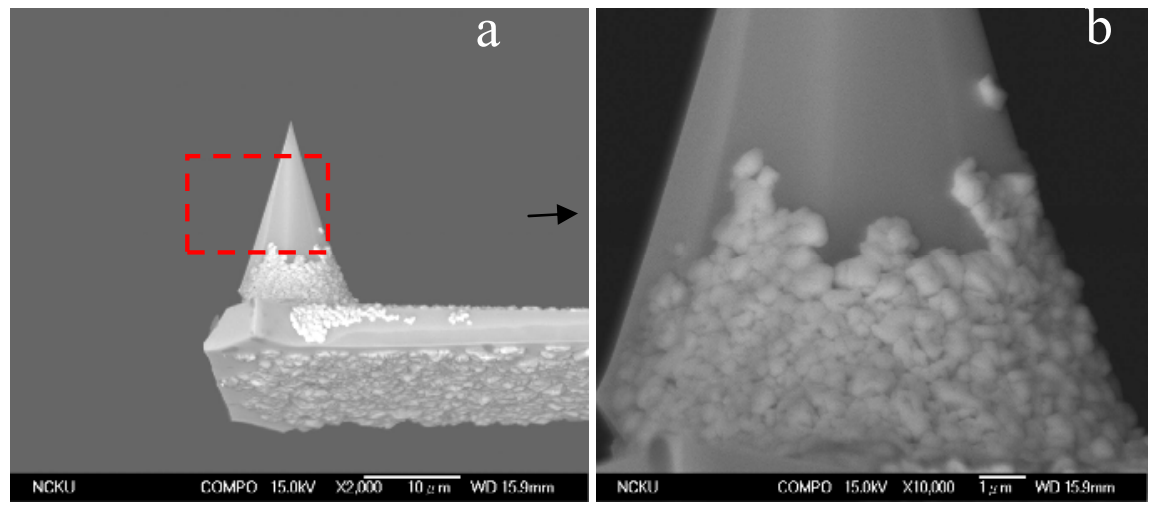

Fig. 11. SEM micrographs illustrating $\mathrm{Cu}$ deposition on the AFM tip at a current density of $0.3 \mathrm{~A} / \mathrm{dm}^{2}$ and plating time of $540 \mathrm{~s}$ (a) $2000 \mathrm{~T}$ (b) $10000 \mathrm{~T}$ magnification of the marked area in red

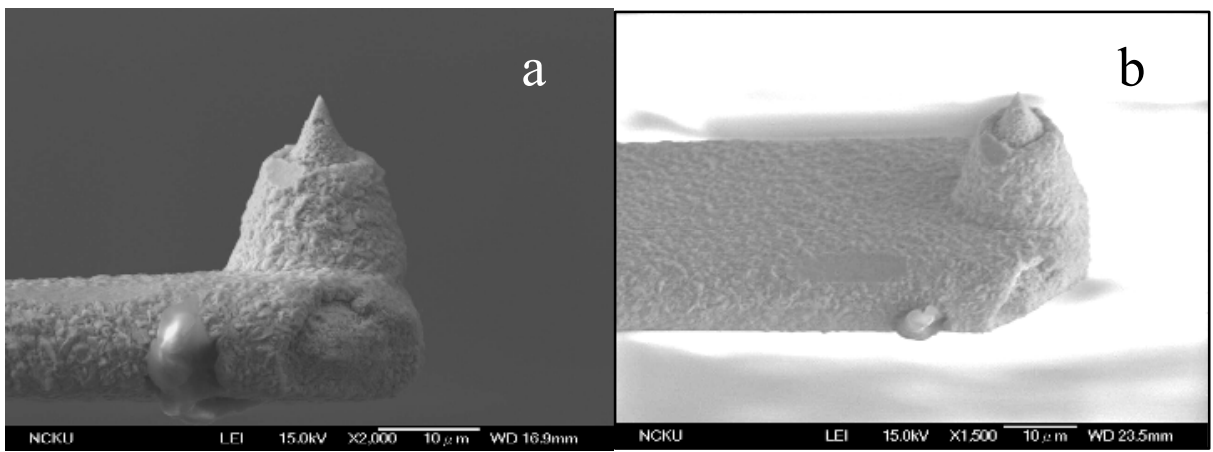

Fig. 12. SEM micrographs illustrating $\mathrm{Cu}$ deposition on the AFM tip at a current density of $0.6 \mathrm{~A} / \mathrm{dm}^{2}$ and plating time of $900 \mathrm{~s}$ (a) SEI image (b) image taken at $35^{\circ}$ tilt (Lin, 2008)
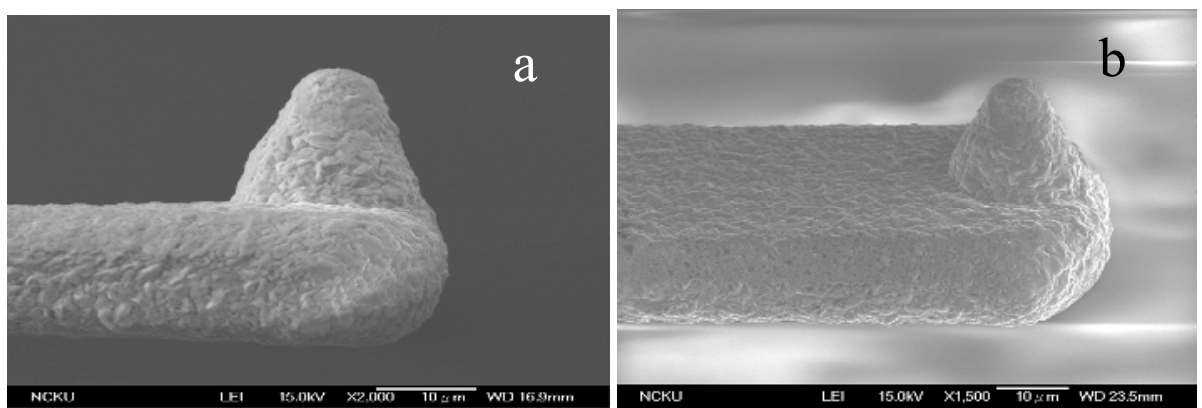

Fig. 13. SEM micrographs illustrating $\mathrm{Cu}$ deposition on the AFM tip at a current density of $0.6 \mathrm{~A} / \mathrm{dm}^{2}$ and plating time of $1200 \mathrm{~s}$ (a) SEI image (b) image taken at $35^{0}$ tilt (Lin, 2008) 
structures- can be suppressed by increasing the electrodeposition current density. In our present case, the crystal growth variation is seen on the open area below the tip and the tip itself. The morphology observed in Fig. 12 is a case of progressive nucleation followed by growth.

As nucleation progresses, the nuclei begins to overlap. Each nucleus is defined by its own diffusion zone through which copper diffuses, thus representing the mass-supply mechanism for continuation of growth. Progressive nucleation corresponds to fast growth of nuclei on many active sites all activated during the course of electroreduction (Pardave et al., 2000). Fig.12b. shows the SEM micrograph for copper deposition at $0.6 \mathrm{~A} / \mathrm{dm}^{2}$ and $900 \mathrm{~s}$ taken at a tilted angle of $35^{\circ}$. Further increase in the plating time to $1200 \mathrm{~s}$ for similar current density resulted in an entirely different morphology from the micrograph shown in Fig. 12. The AFM probe containing the nanoscale AFM tip seems to be entirely covered with copper deposits and also a significant increase in growth and thickness of the deposits are observed in Figs. 13a. Fig. 13b represents the SEM image tilted at an angle of $45^{\circ}$ for clear depiction of the copper deposition on the AFM probe. The copper deposition process on the AFM probe proceeds through instantaneous and progressive nucleation modes for different values of current density. The mechanisms for instantaneous and progressive nucleation modes are described below.

Once nucleation begins, crystals growth may be determined by the rate of charge- transfer or diffusion process. Simple equations have been described (Harrison \& Thirsk, 1971) for two- or three dimensional nucleation and crystal growth processes occurring on a foreign substrate for charge transfer control reactions.

For two-dimensional (2D) instantaneous nucleation and cylindrical growth, current is described by

$$
\mathrm{i}=2 \mathrm{zF} \pi \mathrm{h} \mathrm{N}_{0} \mathrm{k}^{2}{ }_{2 \mathrm{D}}^{\mathrm{t}} / \rho \exp \left(-\pi \mathrm{M}^{2} \mathrm{~N}_{0} \mathrm{k}_{2}{ }^{2} \mathrm{D} \mathrm{t}^{2}\right) / \rho^{2}
$$

And for 2D progressive nucleation

$$
\mathrm{i}=\mathrm{z} \text { FлhMK }{ }_{2}{ }^{2} \mathrm{DA}_{2} \mathrm{Dt}^{2} / \rho \exp \left(-\pi \mathrm{M}^{2} \mathrm{k}_{2}{ }^{2}{ }_{\mathrm{D}} \mathrm{A}_{2 \mathrm{D} \mathrm{t}}{ }^{3} / 3 \rho^{2}\right)
$$

where $\mathrm{k}_{2 \mathrm{D}}$ represents the lateral growth rate constants $\left(\mathrm{mol} \mathrm{cm}^{-2} \mathrm{~s}^{-1}\right), \mathrm{h}$ is the layer height in $\mathrm{cm}, \mathrm{N}_{0}$ represents the total number of active centers $\left(\mathrm{cm}^{-2}\right), \mathrm{A}_{2 \mathrm{D}}$ the nucleation rate (nuclei $\left.\mathrm{cm}^{-2} \mathrm{~s}^{-1}\right), \mathrm{M}$ is the atomic weight $\left(\mathrm{g} \mathrm{mol}^{-1}\right)$ and $\rho$ the density $\left(\mathrm{g} \mathrm{cm}^{-3}\right)$ of the deposit. For these type of mechanisms the current usually increases and then decreases to zero when the surface gets completely covered by two dimensional crystals However, for three dimensional (3D) instantaneous nucleation and growth, the current is depicted by the following equations below.

$$
\mathrm{i}=\mathrm{z} F \mathrm{~K}^{\prime}\left[1-\exp \left(-л \mathrm{M}^{2} \mathrm{k}^{2} \mathrm{~N}_{0} \mathrm{t}^{2} / \rho^{2}\right)\right]
$$

and for 3D progressive nucleation:

$$
\mathrm{i}=\mathrm{zFK}\left[\text { [ 1- } \exp \left(-л \mathrm{M}^{2} \mathrm{k}^{2} \mathrm{~A}_{3 \mathrm{D}} \mathrm{t}^{3} / 3 \rho^{2}\right)\right]
$$

Where $\mathrm{k}$ and $\mathrm{k}^{\prime}$ signify the lateral and vertical growth rate constants $\left(\mathrm{mol} \mathrm{cm} \mathrm{cs}^{-1}\right)$ and $\mathrm{A}_{3 \mathrm{D}}$ the nucleation rate (nuclei $\mathrm{cm}^{2} \mathrm{~s}^{-1}$ ). Hence nucleation and growth phenomena are affected by 
many factors i.e a combination of 2D and 3D growth (Abyaneh \& Fleischmann, 1981; Creus et al., 1992), the death and rebirth of nuclei (Abyaneh \& Fleischmann, 1981) and the secondary three dimensional (3D) growth on top of the first growth layers (Abyaneh et al., 1982).

\subsection{Electron Beam lithography studies}

EBL (Electron-Beam lithography) technique followed soon after the development of the scanning electron microscope (SEM) in 1955 (Smith, 1955) and is one of the earliest processes used for IC fabrication (Buck, 1957). To date, EBL is widely exploited to produce structures in the sub-100 nm range (Allee et al., 1991; Matsui et al., 1989; Sun et al., 2005). Also, as compared with photolithography, the lateral resolution achieved by EBL is higher because the beam of electrons can be focused to produce probe size as small as $1 \mathrm{~nm}$. More over, electrons do not suffer from optical thin-film interference. For ICs, where at present low beam energy and thick conventional resists are employed; electron scattering is the most important factor whereas for nanolithography, which utilizes high beam energy and thin resists, secondary electron emission is the most dominant factor. The resolution of EBL is also dependent on the chemical nature of the resist. Recently, new class of resists such as organic self-assembled mono layers (SAMs) has been developed to fabricate structures below $10 \mathrm{~nm}$ (Golzhauser et al., 2000; Lercel, 1996) Currently, electron beam lithography is used principally in support of the integrated circuit industry, where it has three niche markets. The first is in maskmaking, typically the chrome-on glass masks used by optical lithography tools. It is the preferred technique for masks because of its flexibility in providing rapid turnaround of a finished part described only by a computer. The ability to meet stringent line width control and pattern placement specifications, on the order of 50 $\mathrm{nm}$ each, is a remarkable achievement.

\subsubsection{Principle of EBL}

The principle of pattern transfer based on EBL consists of several process steps. The process steps are essentially the same as those used for photolithography, except that the pattern on the resist is formed by scanning directly the focused particle beam across the surface. The lithographic sequence usually begins with coating of substrates with a positive or negative resist. Positive resists such as poly (methyl-methacrylate) (PMMA) used in the present chapter become more soluble in a developing solvent after exposure because the radiation causes local bond breakages and thus chain scission. This causes the exposed regions containing material of lower mean molecular weight to dissolve after the development. Nevertheless, negative resists become less soluble in solvent after exposure because crosslinking of polymer chains occurs. If in case, a region of a negative resist-covered film is exposed, only the exposed region will be covered by the resist after development. Subsequently, the resist-free parts of the substrate can be selectively coated with metal or etched before removal of the unexposed resist thus leaving the desired patterns at the surface. Fabrication of metallic nanostructures has been widely explored using conventional EBL and lift off techniques. However, this top-down approach cannot be employed for the fabrication of high aspect ratio vertical structures since gradual accumulation of materials at the top of the resist blocks and closes the opening of the structures during the evaporation of metal. Electrodeposition of metals into the holes formed in presence of PMMA resist is a 
convenient alternative to solve this problem (Simon et al., 1997). The fabrication of dense ultra-small magnetic arrays by filling nanoholes with electrodeposited $\mathrm{Ni}$ has been demonstrated (Xu et al., 1995).

\subsubsection{EBL induced Copper deposition}

Electron beam lithography technique is used in the present study to enable selective electrodeposition of $\mathrm{Cu}$ on the AFM tip and the open area beneath it. The selective electrodeposition of $\mathrm{Cu}$ on n-type $\mathrm{Si}$ (111) surfaces covered with organic monolayers by using e-beam lithographic techniques has been reported (Balaur et al., 2004). Selective copper deposition on e-beam patterned alkane and biphenylthiols has been reported (Kalten Poth et al., 2002) at suitable deposition potentials. 1-octadecanethiol (ODT) was used as a "positive template" leading to copper deposition only on the irradiated parts, 1,1'-biphenyl4-thiol ( BPT) on the other hand acted as a "negative template," where the irradiated and cross-linked biphenyl layer exhibited a blocking behavior, allowing copper deposition on the non-irradiated parts. In the present study, the open area of the nanosize AFM tip was selectively exposed to the e-beam. It is noticed that copper electrodeposition occurs on the exposed area of the AFM tip. For the copper electrodeposition process, the current density applied was $0.6 \mathrm{~A} / \mathrm{dm}^{2}$, and the electrodeposition time was varied from 300 to $2400 \mathrm{~s}$.
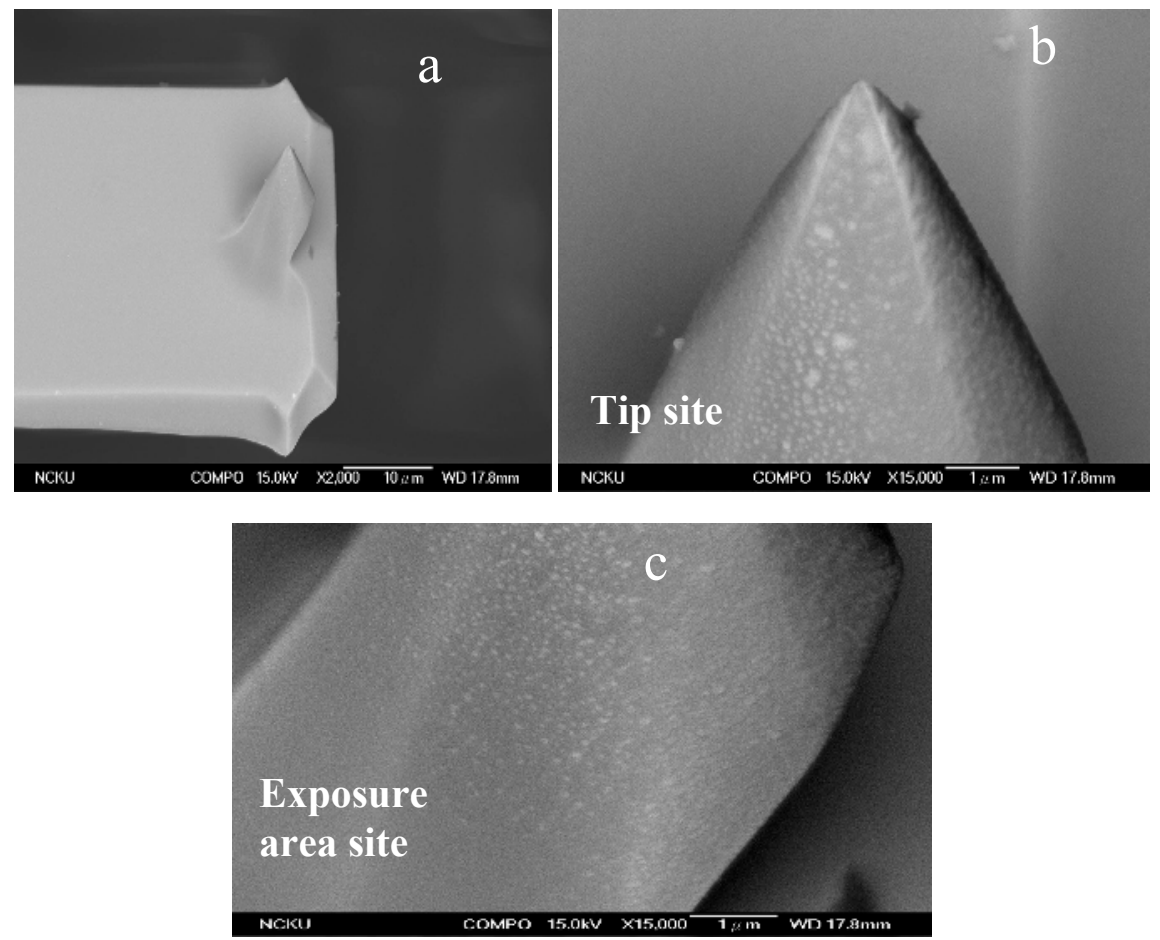

Fig. 14. SEM micrograph demonstrating $\mathrm{Cu}$ deposition on the AFM tip after EBL treatment under current density of $0.6 \mathrm{~A} / \mathrm{dm}^{2}$ and electrodeposition time of $300 \mathrm{~s}$ (a) BEI image

(b) Image taken at the tip site (c) Exposure area site 
SEM micrographs for copper electrodeposition on the AFM tip and the open area beneath it for various deposition times (i.e 300, 600, 1200, $2400 \mathrm{~s}$ ) and current density of $0.6 \mathrm{~A} / \mathrm{dm}^{2}$ are presented in Figs. 14-17.These SEM micrographs were taken after exposure to the electron beam. In Figs. 14 (a) - (c) the micrographs for copper deposition on the AFM tip under current density of $0.6 \mathrm{~A} \mathrm{dm}^{-2}$ and electrodeposition time of $300 \mathrm{~s}$ are clearly depicted. Copper deposition is found to be minimum and non-uniform in these images. Further increase in the electrodeposition time to $600 \mathrm{~s}$ for the similar current density and exposure to the e-beam increases the amount of copper deposits on the nanosize AFM tip and the open area beneath it (Fig. 15 a). SEM micrographs in Fig. 15b and 15 c refers to the magnified images of the AFM tip and the exposed site.
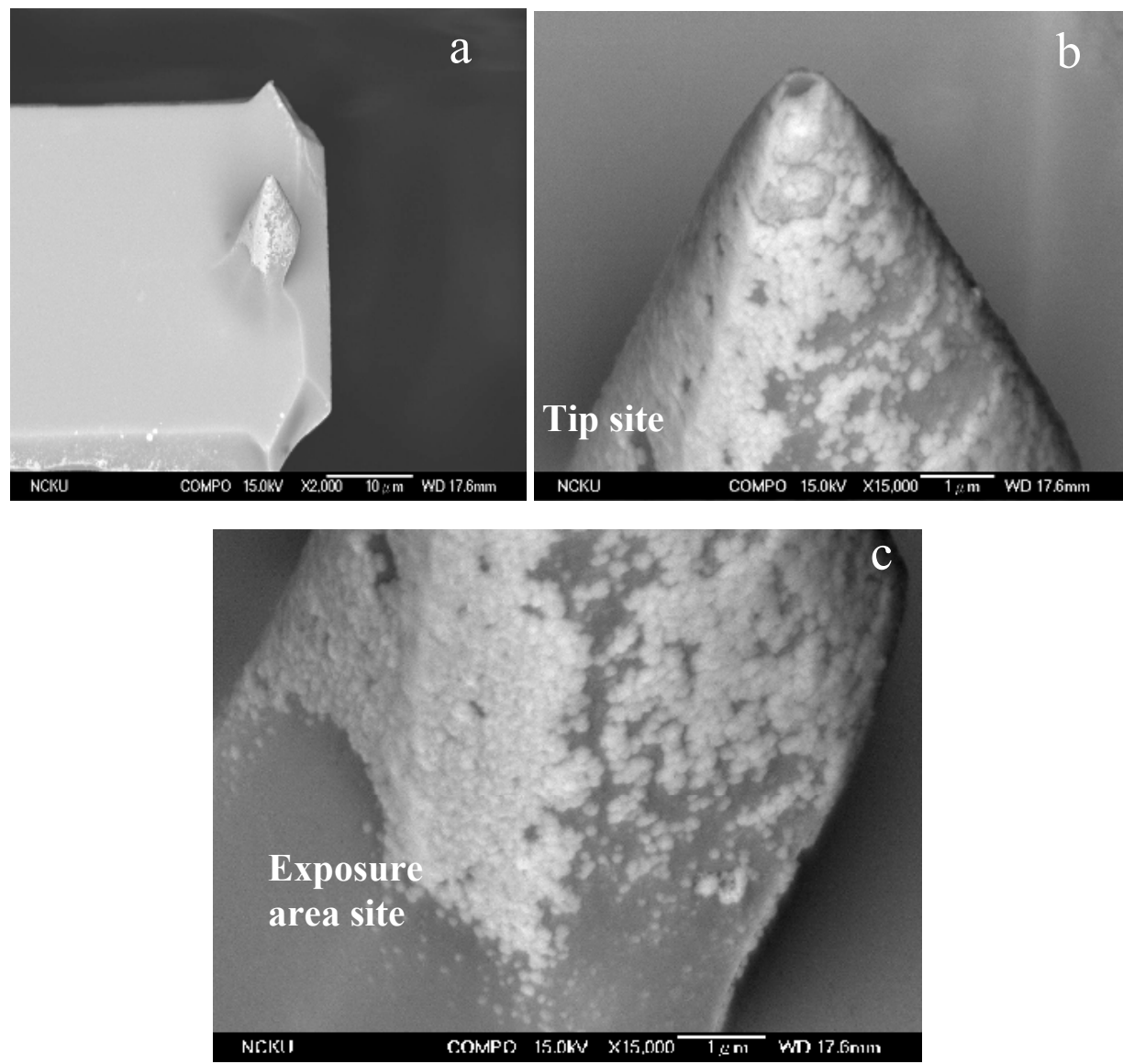

Fig. 15. SEM micrograph demonstrating Cu deposition on the AFM tip after EBL treatmentunder current density of $0.6 \mathrm{~A} / \mathrm{dm}^{2}$ and electrodeposition time of $600 \mathrm{~s}$ (a) BEI image (b) Image taken at the tip site (c) Exposure area site

The micrographs reveal that copper deposition is not uniform in the open area beneath the AFM tip. However a significant change in the morphology of copper deposits is 
observed when the electrodeposition time was increased to $1200 \mathrm{~s}$. SEM micrograph in Fig. 16a shows that an uniform layer of copper is deposited on the AFM tip and the open area beneath the tip. These results indicate that the exposure of the tip to the high energy electron beam might have facilitated the electrodeposition of copper on the tip. The micrographs in Fig. $16 \mathrm{~b}$ reveal that some copper is being deposited on the edges of the cantilever. This is because the PMMA layers on the edges are found to be thinner than on the platform. Those places are not exposed to the e-beam; therefore the developer could dissolve the PMMA layer on the edges and hence copper deposition took place on the edges. The overpotential required to deposit copper on the edges is lower than on the AFM tip.
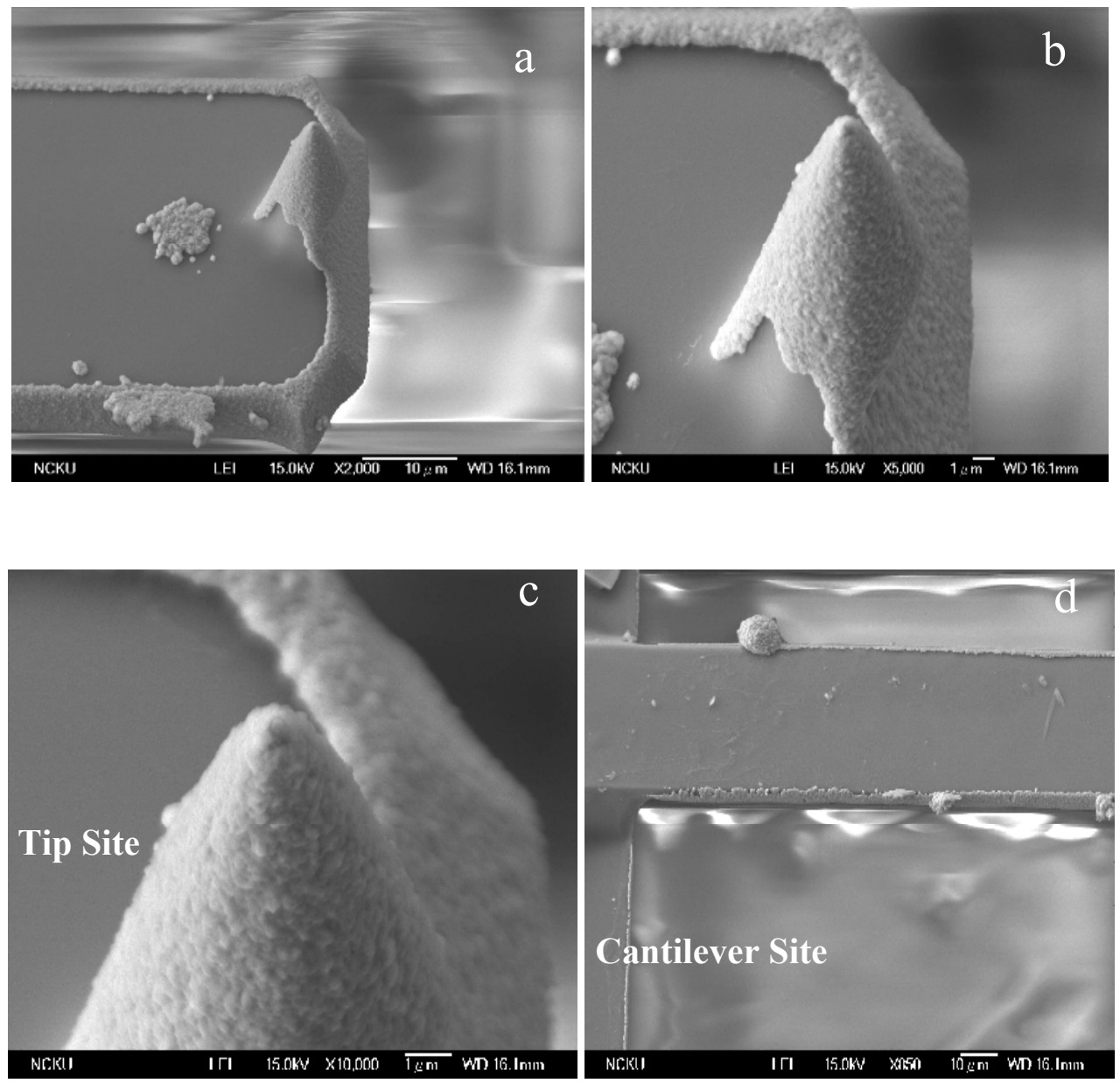

Fig. 16. SEM micrograph demonstrating Cu deposition on the AFM tip after EBL treatment under current density of $0.6 \mathrm{~A} / \mathrm{dm}^{2}$ and electrodeposition time of $1200 \mathrm{~s}$ (a) SEI image (b) Magnified to $5000 \mathrm{~T}$ (c) Tip site (d) Cantilever site 
Theoretically it has been established (West, 1971) that deposition at low overpotentials is dominated by surface diffusion; hence nucleation and growth occur primarily at step edges and dislocations (Winand, 1975). Fig. 17 illustrates the morphology of copper deposition on the nanosize AFM tip obtained under current density of $0.6 \mathrm{~A} / \mathrm{dm}^{2}$ and electrodeposition time of $2400 \mathrm{~s}$ and after exposure to the e-beam. The micrograph in Fig.17a distinctly shows that copper is deposited on the AFM tip and a very thick growth of copper deposits is seen on the open area beneath the tip. From the series of micrographs obtained at different electrodeposition times and current density of $0.6 \mathrm{~A} / \mathrm{dm}^{2}$, it is noticed that copper gets deposited both on the AFM tip and the open area beneath it, the most uniform deposition seen at $2400 \mathrm{~s}$ of electrodeposition time.
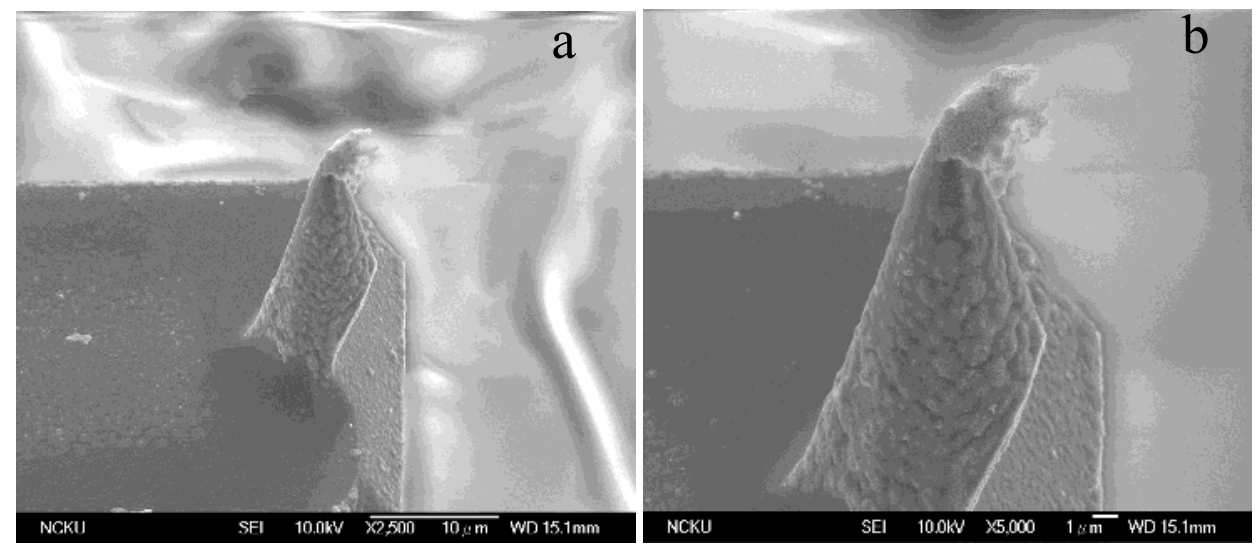

Fig. 17. SEM micrograph demonstrating Cu deposition on the AFM tip after EBL treatment under current density of $0.6 \mathrm{~A} / \mathrm{dm}^{2}$ and electrodeposition time of $2400 \mathrm{~s}$ (a) SEI image (b) Magnified to $5000 \mathrm{~T}$

The PMMA coated on the AFM tip becomes more soluble in a developing solvent after exposure to the e-beam because the radiation causes local bond breakages and thus chain scission (Djenizian et al., 2006) as mentioned above. It could be clearly seen from Fig. 17b 
that the unexposed areas below the AFM tip remain covered with PMMA. However, the resist free parts of the AFM tip are selectively coated with copper. Reports on the selective electrodeposition of $\mathrm{Cu}$ (Balaur et al., 2004) on n-type Si (lllll) surfaces covered with organic monolayers and e-beam modified using e-beam lithographic techniques have also been established. Copper was electrochemically deposited in the e-beam modified regions and the selectivity of the deposition of copper in these regions was strongly dependent on the applied e-beam dose. The selective deposition of copper on the nanosize AFM tip can be described on the basis of Volmer-Weber approach which states that higher numbers of activation sites are triggered with a higher overvoltage. In the Volmer-Weber model, nucleation and growth are strongly potential dependent. At low cathodic potentials, only a few sites are involved because the energy level is not sufficient whereas at high cathodic voltages more initiation sites contribute to the nucleation process. It implies that at low overpotentials the crystallites have to grow extremely large to reach coalescence and form a homogenous deposit. In the present study, higher overpotential existing on the AFM tip might have increased the number of activation sites, leading to the preferential deposition of copper on exposure to the e-beam.

\section{Conclusion}

The investigations made in this chapter have highlighted electrodeposition as an attractive approach for the preparation of nanostructured materials. Copper electrodeposition on a nanosize AFM tip of diameter $80 \mathrm{~nm}$ was established by varying the magnitude of current densities with electrodeposition time and vice versa. Significant changes in the morphology of copper deposits were observed with changes in the above parameters. Morphological investigations by SEM revealed that a nonuniform layer of copper was formed on the open areas surrounding the tip and the AFM probe; however, deposition of copper on the AFM tip could not be achieved in the absence of photoresist. Electron beam lithography technique facilitated the formation of copper deposits on the nanosize AFM tip of diameter $80 \mathrm{~nm}$ in the presence of PMMA. Copper was electrochemically deposited on the e-beam modified regions of the AFM probe at a current density of $0.6 \mathrm{~A} / \mathrm{dm}^{2}$ with electrodeposition times ranging from 300 to $2400 \mathrm{~s}$. The most uniform deposition on the AFM tip was noticed after EBL treatment under current density of $0.6 \mathrm{Adm}^{-2}$ and electrodeposition time of $2400 \mathrm{~s}$.

\section{Acknowledgment}

The authors acknowledge financial support of this study from the National Science Council of China under NSC 94-2811-E-006-021. The Department of Materials Science and Engineering, National Cheng Kung University assisted in meeting the publication costs of this article.

\section{References}

Abyaneh, M.Y.; Hendrikx. J.; Visscher, W. \& Barendrecht. E (1982). Studies of Electroplating using an EQCM. I. Copper and Silver on Gold. Journal of Electrochemical Society, Vol. 129, No.12 (December 1982) pp.2654-2659., ISSN 0013-4651. 
Abyaneh, M.Y.\& Fleischmann, M. (1981), The Electrocrystallisation of Nickel. Journal of Electroanalytical Chemistry, Vol. 119, No. 187, pp. 197, ISSN 1572-6657.

Andricacos, P. C. ; Uzoh, C.; Dukovic, J. O.; Horkans, J. ; Deligianni, H (1998) Damascene copper electroplating for chip interconnections IBM J. Res. Develop Vol 42 (April 2010) No.5, 567-574, ISSN:0018-846.

Andricacos, P. C (1999) Copper on Chip Interconnections -A Breakthrough in Electrodeposition to make better chips, Interface 1999, 8,32.

Allee, D. R.; Umbach, C.P. \& Broers, A.N. (1991). Direct nanometer scale patterning of $\mathrm{SiO}_{2}$ with electron- beam irradiation. Journal of Vaccuum Science and Technology B, Vol. 9, No.16 (November 1991)pp.2838-2841, ISSN 1071-1023.

Allongne, P.A. (1995) in Advances in Electrochemical Science and Engineering, (eds : Gerischer, H. \& Tobias, C. W), ISBN 3-527-28273-4,Weinheim, Germany.

Balaur, E. ; Djenizian, T.; Boukherroub, R.; Chazalviel, J. N. ; Ozanam, F. \& Schmuki, P. Electroplating: an alternative transfer technology in the $20 \mathrm{~nm}$ range. Electrochemistry Communications. Vol.6, No.2, (February 2004), pp. 153-157, ISSN 1366-2481.

Batina, K. \& Nichols, D.M. (1992). An in situ scanning tunneling microscopy study of the initial stages of bulk copper deposition on gold(100): the rim effect. Langmuir, Vol.8, No.10 (Oct 1992) pp.2572-2576, ISSN 0743-7463.

Benenz, P.; Xiao, X. Y.\& Baltruschat, H. (2002). Tip-Induced Nanostructuring of a Clean and Ethene -modified Pt (111) Electrode with Cu. Journal of Physical Chemistry B, Vol. 106, No. 14, ( March 2002) pp 3673-3680, ISSN 1089-5647.

Binning, G. \& Rohrer, H. (1982). Scanning Tunneling Microscopy. Helvetica Physica Acta, Vol. 55, pp.726-735, ISSN 0036-8075.

Bockris J. O.M. \& Razumney, G. A. (1967) Fundamental Aspects of Electrocrystallization, Plenum Press, New York.

Buck, D.A. \& Shoulders. K (1957), In Proceedings Eastern Joint Computer Conference (ATTE, New Yoork), p.55.

Budevski, E. ; Staikov, G. \& Lorenz, W. J. (1996) Electrochemical Phase Formation and Growth An Introduction to the Initial Stages of MetalDeposition, ISBN 3527294228978352729 4220,VCH, Weinheim.

Budevski, E.; Bostanov, V. \& Staikov, G. (1980) Annu. Rev. Mater. Sci. 10, 85.

Budevski E. (1983) Comprehensive Treatise of Electrochemistry, Vol. 7 (Eds: B. E.Conway, J. O'M. Bockris, E. Yeager, S. U. M. Kahn, R. E. White, Plenum Press, New York, p.399.

Budevski, E. .; Staikov, G. \& Lorentz, W. (1996). An Introduction to Initial Stages of MetalDeposition, p. 4, Wiley VCH, ISBN 3527294228, Weinheim, Germany.

Carlsson, P.; Holmstriom, B. ; Kita H. \& Uosaki, V. (1990). Novel application of scanning tunneling microscopy - tip current voltammetry of n-GaAs and p-GaP in electrolyte solution.Surface Science, Vol. 237, No.1-3 (November 1990) pp. 280 -290, ISSN 0039-6028.

Chang, S.C. ; Shieh, J.M. ; Lin, K.C.; Dai, B.T. ; Wang, T.C.; Chen, C.F. ; Feng, M.S. ; Li, Y.H. \& Lu, C.P. (2001). Investigations of effects of bias polarization and chemical parameters on morphology and filling capability of $130 \mathrm{~nm}$ damascene 
electroplated copper. Journal of Vacuum Science and Technology B. Vol.19 , No.3 (May 2001) pp. 767-774, ISSN 1071-1023.

Creus ,H. A.; Carro, P.; Gonzalez, S.; Salvarezza, R.C \& Arvia, A.J. (1992). Electrochemical kinetics and growth modes of silver deposits on polyfaceted platinum spherical electrodes Electrochmica Acta, Vol. 37, No. 12, (September 1992), pp. 2215-2227, ISSN 0013-4686.

Danilov, A. I., Molodkina, E. B \& Polukarov Yu. M. (1994) Russ. J.Electrochem. 1994, 30, 674.

Djenizian, T. \& Schmuki, P. (2006) Electron beam lithographic techniques and electrochemical reactions for the micro- and nanostructuring of surfaces under extreme conditions. Journal of Electroceramics, Vol. 16, No.1, (Feb 2006), pp.9-14, ISSN 1385-3449.

Fischer, H. (1954) Elektrolytische Abscheidungund Elektrokristallisation von Metallen,Springer, Berlin

Fischer, H. (1969) Electrocrystallisation of Metals under ideal and real conditions. Angew. Chem. Int. Ed.Engl. , 8, 108-119, ISSN 1521-3773.

Fleischmann, M. \& Thirsk, H. R. (1963). Advances in Electrochemistry and Electrochemical Engineering, Vol. 3, P. Delahay (Ed.), Wiley, New York.

Fu, C. X.; Shen, W. X. \& Yao T. T. (1990) Physical Chemistry, 4th ed., p. 603, Higher Education Press, Beijing.

Gewirth, A.A. \& Siegenthaler (1995), Nanoscale Probes of the Solid/ Liquid Interface, NATO ASI series E: Applied sciences vol. 288 , 334 pp, ISBN 0-7923-3454-X, Kluwer Academic Publishers, Dordrecht/ Boston/ London.

Gileadi, E. \& Tsionsky, V. Studies of Electroplating Using an EQCM. I. Copper and Silver on Gold. Journal of Electrochemical Soc.iety. vol. 147, No.2 (Feb 2000) pp. 567-574, ISSN 0013-4651.

Golzhauser, A.; Geyer, W.; Stadler, V.; Eck, W.; Grunze, M.; Edinger, K.; Weimann, Th.\& Hinz. P (2000). Nanoscale patterning of self-assembled monolayers with electrons. Journal of Vacuum Science and Technology. B, Vol. 18, No.6 (November 2000) 34143418, ISSN 1071-1023.

Hachiya, T.; Honbo, H. \& Iteya, K (1991). Detaled Underpotential Deposition of Copper on Gold (111) in aqueous-Solutions. Journal of Electroanalytical Chemistry, Vol. 315, pp.275-291, ISSN 1572-6657.

Hozzle, M. H.; Zwing, V \& Kolb D. M (1995). The influence of steps on the deposition of Cu on $\mathrm{Au}$ (III) Electrochimica Acta , Vol 40, No. 10,pp 1237-1247, ISSN 0013-4686 (95) 00055-0.

Harrison, J.A. \& Thirsk, H. R. (1971), A guide to the study of electrode kinetics, In :Electroanalytical Chemistry, A. J. Bard, (Ed.), Vol5, 67, Marcel Dekker, London.

KaltenPoth, G.; Volkel, B.; Nottbohm, C.T.; Golzhauser.A \& Buck, M. (2002). Electrode modification by electron-induced patterning of self-assembled monolayers. Journal of Vacuum Science and Technology B, Vol.20 , No.6 (November 2002), pp 2734-2738, ISSN 1071-1023. 
Kelber, J..; Rudenja, J. \&. Bjelkevig, C. (2006) Electrodeposition of copper on Ru $\left(\begin{array}{llll}0 & 0 & 0 & 1\end{array}\right)$ in sulfuric acid solution: Growth kinetics and nucleation behavior. Electrochimica Acta, Vol.51, No.15, (April 2006) pp.3086-3090, ISSN 0013-4686.

Koinuma, M. \& Uosaki, K (1994) In situ observation of anodic dissolution process of n-GaAs in $\mathrm{HCl}$ solution by electrochemical atomic force microscope. Journal of Vaccum Science and Technology B, Vol.12, pp 1543-1546, ISSN 1071-1023.

Lercel, M. J.; Craighead, H. G.; Parikh, A.N.; Seshadri, K. \& Allana, D. L. (1996), Sub-10 nm lithography with self-assembled monolayers. Applied Physics Letters, Vol. 68, No.11, pp.1504-1506, ISSN 0003-6951.

Lin, K.L.; Chen, S.Y. \& Mohanty, U.S (2008) Effect of Current density and Plating Time on the Morphology of Copper Deposits on an AFM tip. Journal of Electrochemical Society. Vol. 155, No. 4, pp. D251-D255, ISSN 0013-4651.

Li, Y.; Maynor, B.W. \& Lu. J (2001). Electrochemical AFM “Dip-Pen” Nanolithography. .Journal of American Chemical Society, Vol. 123, No.9 (March 201) 2105-2106, ISSN 0002-7863.

Lustenberger, P.; Rohrer, H; Christoph, R \& Stegenhaler, H. (1988) Journal of Electroanalytical Chemistry, Vol. 243, pp.225.

Matsui, S.; Ichihashi, T .\& Mito, M. (1989). Electron beam induced selective etching and deposition technology. Journal of Vacuum Science and Technology B, Vol. 7, No.15 September 1989) pp.1182-1190, ISSN 1071-1023 .

Markovic, N.M.; \& Ross, P.N, Jr (1993). Electrodeposition of copper on Pt (111) and Pt (100) single crystal surfaces, Journal of Vacuum Science and Technology A, Vol. 11, No.4, pp. 2225-2232, ISSN 0734-2101.

Michailova, E. ; Vitanova, I.; Stoychev, D. \& Milchev, A. (1993). Initial stages of Copper Electrodeposition in presence of organic additives. Electrochimica Acta 1993, 38, 2455-2458, ISSN 0013-4686 (93) 85116-G.

Milchev, A.. (1997). Electrochemical alloy formation-theory of progressive and instantaneous nucleation without overlap. Electrochimica Acta. Vol. 42, No.10, pp. 1533-1536, ISSN 0013-4686.

Milchev, A (2002) Electrocrystallization:Fundamentals of Nucleation and Growth, ISBN 1-40207090-X, Kluwer Academic Publishers,Boston/Dordrecht/London.

Nichols, R. J.; Beckman.; Mayer, H.; Batina, N \& Kolb, D.M (1992). An in situ scanning tunnelling microscopy study of bulk copper deposition and the influence of an organic additive. Journal of Electroanalytical Chemistry, Vol. 330, No.1-2 (July 1992) pp. 381-394, ISSN 1572-6657.

Oskam, G.; Long, J. G.; Natarajan, A. ; Searson, P. C (1998) Electrochemical deposition of metals onto silicon. J. Phys. D: Appl. Phys. Vol. 31, No.16 (August 1998), pp.19271949, ISSN 0022-3727.

Pardave, M. P.; Ramirez, M. T. ; Gonzalez, I.; \& Scharfiker, B. R. (2000). J. Electrochem. Soc., $147,567(200)$

Paunovic, M. \& Schlesinger, M. (2006) Fundamentals of Electrochemical Deposition, ISBN 978-0471-71221-3, Wiley-Interscience, NewYork.

Seah, C. H.; Mridha, S; Chan, L.H (1998), Growth morphology of electroplated copper: effect of seed material and current density, IITC, 98-158, IEEE, ISSN 0-7803-4285-2/98. 
Seah, C.H.; Mridha, S \& Chan, L.H (1999), Fabrication of D.C.-plated nanocrystalline copper electrodeposits. Journal of Materials Processing Technology, Vol. 89-90 , (May 1999), pp.432-436, ISSN 0924-0136.

Simon, G.; HaghiriGosnet, A.M.; Carcenac, F. \& Lannois, H (1997), Electroplating: An alternative transfer technology in the 20nm range. Microelectronics Engineering, Vol. 35, No. 1-4 (February 1997), pp.51-54, ISSN 0167-9317.

Smith, K.C. A \& Oatley, C.W (1955). Brazilian Journal of Applied Physics, Vol. 6, pp.391.

Sonnenfeld, R. \& Hannsma, P.K (1986) Atomic Resolution Microscopy in Water, Science, Vol. 232, No.4747, pp.211-213, ISSN 0036-8075.

Staikov, G.; Juttner, K.; Lorenz, W. J \& Budevski, E (1994). Metal depsoition in the nanometer range.,Electrochimica Acta, Vol. 39, No.8-9, (June 1994), pp. 1019-1029, ISSN 0013-4686.

Stegenthaler, H (1992). in Scanning Tunneling Microscopy II, Springer Ser. Sur. Sci, Vol. 28(eds: Ewisendanger, R.; Guntherodt, H. J, Springer, Berlin.

Sun, S.; Chong, K. S. L and Leggett, G.J (2005). Photopatterning of self-assembled monolayers at $244 \mathrm{~nm}$ and applications to the fabrication of functional microstructures and nanostructures, Nanotechnology, 16, pp.1798-1808, ISSN 09574484 .

Takahashi, K.M. \& Gross, M.E. (1999). Transport Phenomena That Control Electroplated Copper Filling of Submicron Vias and Trenches. Journal of Electrochemical Society. Vol. 146, No.12 ( December 1999) pp. 4499-4503,.

Takahashi, K.M. (2000). Electroplating Copper onto Resistive Barrier Films. Journal of Electrochemical Society. Vol. 147, No.4 (April 2000) pp 1414- 1417, ISSN 00134651.

Tan, M. \& Harb, J.N. (2003) Additive Behavior during Copper Electrodeposition in Solution Containing Cl-, PEG, and SPS Journal of Electrochemical Soc.iety. Vol.150, pp C420C425, ISSN 0013-4651.

Teh, W.H.; Koh, L.T.; Chen, S.M.; Xie, J.; Li, C.Y. \& Foo, P.D. (2001) Study of microstructure and resistivity evolution for electroplated copper films at near-room temperature. Microelectronics Journal, Vol 32, No.7 (July 2001), pp. 579-585, ISSN 0026-2692.

Thirsk, H. R. \& Harrison, J. A. (1972), A guide to the study of electrode kinetics, ISBN 0126877505, London, New York, Academic Press.

Volmer, M (1934) Das Elektrolytische Kristallwachstum, Hermannet Cie, Paris.

Volmer, M (1939) Kinetik der Phasenbildung, Steinkopf, Dresden.

West, J. M. (1971). Electrodeposition and Corrosion Process, pp. 204, 2nd Edition, ISBN 97804422093525, Van Nostrand Reinhold, New York.

Winand, R (1975). Electrocrystallisation of Copper. Transactions of the Institution of Mining and Metallurgy. Section C, Mineral processing and extractive metallurgy, Vol.84,pp.6775, ISSN 0371-8553.

Xu, W.; Wong, J.; Cheng, C.C.; Johnson, R. \& Scherer.A. (1995), Fabrication of ultrasmall magnets by electroplating. Journal of Vacuum Science and Technology, B. Vol. 13, No.6 (November 1995) pp.2372-2375, ISSN 1071-1023. 
Yau, S.L.; Gao, X; Chang, S.C; Schardt, B.C \& Weaver, M. J.(1991) Atomic-resolution scanning tunneling microscopy and infrared spectroscopy as combined in situ probes of electrochemical adlayer structure: carbon monoxide on rhodium (111). Journal of American Chemical Society, Vol. 113, No.16, pp. 6049-6056, ISSN 00027863. 


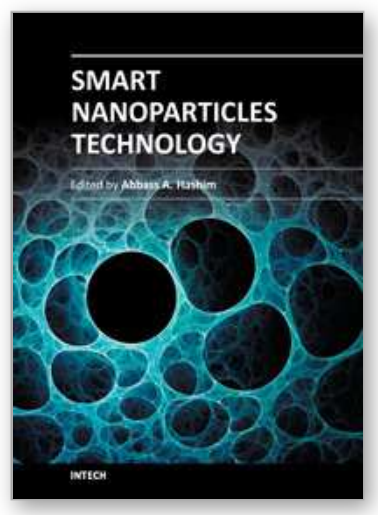

\author{
Smart Nanoparticles Technology \\ Edited by Dr. Abbass Hashim
}

ISBN 978-953-51-0500-8

Hard cover, 576 pages

Publisher InTech

Published online 18, April, 2012

Published in print edition April, 2012

In the last few years, Nanoparticles and their applications dramatically diverted science in the direction of brand new philosophy. The properties of many conventional materials changed when formed from nanoparticles. Nanoparticles have a greater surface area per weight than larger particles which causes them to be more reactive and effective than other molecules. In this book, we (InTech publisher, editor and authors) have invested a lot of effort to include 25 most advanced technology chapters. The book is organised into three well-heeled parts. We would like to invite all Nanotechnology scientists to read and share the knowledge and contents of this book.

\title{
How to reference
}

In order to correctly reference this scholarly work, feel free to copy and paste the following:

Udit Surya Mohanty, S. Y. Chen and Kwang-Lung Lin (2012). Nanoscale Electrodeposition of Copper on an AFM Tip and Its Morphological Investigations, Smart Nanoparticles Technology, Dr. Abbass Hashim (Ed.), ISBN: 978-953-51-0500-8, InTech, Available from: http://www.intechopen.com/books/smart-nanoparticlestechnology/nanoscale-electrodeposition-of-copper-on-an-afm-tip-and-its-morphological-investigations

\section{INTECH}

open science | open minds

\section{InTech Europe}

University Campus STeP Ri Slavka Krautzeka 83/A 51000 Rijeka, Croatia

Phone: +385 (51) 770447

Fax: +385 (51) 686166 www.intechopen.com

\section{InTech China}

Unit 405, Office Block, Hotel Equatorial Shanghai

No.65, Yan An Road (West), Shanghai, 200040, China 中国上海市延安西路65号上海国际贵都大饭店办公楼 405 单元 Phone: +86-21-62489820

Fax: $+86-21-62489821$ 
(C) 2012 The Author(s). Licensee IntechOpen. This is an open access article distributed under the terms of the Creative Commons Attribution 3.0 License, which permits unrestricted use, distribution, and reproduction in any medium, provided the original work is properly cited. 